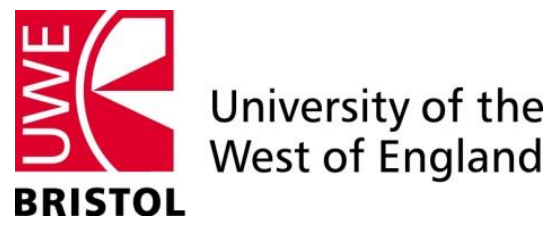

Faculty of Business and Law

\title{
Using CHARM to adjust for cross-hauling: the case of the Province of Hubei, China
}

\author{
Anthony T. Flegg ${ }^{1}$, Yongming Huang ${ }^{2}$ and Timo Tohmo \\ ${ }^{1}$ University of the West of England, Bristol, UK \\ ${ }^{2}$ Wuhan University, Wuhan, China \\ ${ }^{3}$ University of Jyväskylä, Jyväskylä, Finland
}

Economics Working Paper Series

1506 


\title{
Using CHARM to Adjust for Cross-Hauling: The Case of the Province of Hubei, China
}

\author{
Anthony T. Flegg \\ Department of Accounting, Economics and Finance, University of the West of England, Bristol, UK \\ Email: tony.flegg@uwe.ac.uk \\ Yongming Huang \\ Center for Industry-University-Research Collaboration, Institute for Development of Central China, \\ Wuhan University, Wuhan, China \\ Corresponding author \\ Email: hym@whu.edu.cn
}

Timo Tohmo

School of Business and Economics, University of Jyväskylä, Jyväskylä, Finland

Email: timo.tohmo@jyu.fi

\begin{abstract}
Data for the Chinese province of Hubei are used to assess the performance of Kronenberg's CHARM, a method that takes explicit account of cross-hauling when constructing regional input-output tables. A key determinant of cross-hauling is held to be the heterogeneity of commodities, which is estimated using national data. However, contrary to the authors' findings for Finland, CHARM does not generate reliable estimates of Hubei's sectoral exports, imports and volume of trade, although it is more successful in estimating sectoral supply multipliers. The poor simulations of regional trade are attributed to the fact that Hubei is a relatively small region, where there is a large divergence between regional and national technology and pattern of final demand. The simulation errors are decomposed into components reflecting differences between regional and national technology, final demand and heterogeneity. The third component is found to be the least important of the three sources of error.
\end{abstract}

Keywords: Regional input-output tables; Non-survey methods; CHARM; Cross-hauling; China

\section{INTRODUCTION}

Regional input-output tables are a very useful tool for regional planning, yet constructing a survey-based regional table can be a complex, expensive and lengthy task. Consequently, analysts typically endeavour to 'regionalize' the national table, so that it corresponds as far as possible to a region's economic structure (Jackson, 1998). However, standard methods of regionalization - especially those based on the commodity balance (CB) method or on simple location quotients (SLQs) - are prone to understate interregional trade. This problem occurs because these methods disregard cross-hauling (the simultaneous exporting and importing of a given commodity) and do not consider a region's relative size.

In an effort to tackle the problem of cross-hauling, Kronenberg (2009) proposed an innovative new non-survey routine for constructing regional tables, the Cross-Hauling Adjusted Regionalization Method (CHARM). CHARM incorporates a systematic procedure for adjusting the volume of imports and exports to allow for cross-hauling, which is held to vary directly with the heterogeneity of products, along with regional output and demand.

Whereas abundant empirical evidence exists on the relative performance of the SLQ and related techniques, little is known about the likely effectiveness of CHARM as a way of regionalizing national input-output tables. In fact, the only empirical studies currently available are those by Flegg and Tohmo (2013a), who examined data for Finland and its largest province, Uusimaa, and Kronenberg and Többen (2013), who studied data for the German federal state of Baden-Württemberg. More tests are clearly needed, especially for 
countries less economically advanced than Finland and Germany.

A notable exception to the paucity of survey-based regional tables is China, where regional tables for most provinces and municipalities are constructed quinquennially. This study focuses on the province of Hubei, which was chosen owing to its diversified regional economy and key position in central China, along with the extensive knowledge of Hubei's economy of one of the present authors. Our primary aim is to use the published tables for Hubei and China to carry out a detailed empirical test of CHARM's performance. As far as the authors are aware, this is the first study to have used Chinese data in this way.

The present study builds upon the work of Flegg and Tohmo (2013a) in two important respects. The first is that Finland and China differ greatly in terms of variables such as income per head, the size and composition of GDP, population and surface area. It is of interest, therefore, to see whether such disparities affect CHARM's performance. Secondly, the input-output table for Hubei is more detailed than that for Uusimaa, with forty-two rather than twenty-four sectors, including seventeen separate types of manufacturing. This finer detail makes it possible to perform a more searching analysis.

The next section gives an overview of Hubei's economy. The theoretical foundations of CHARM are examined in the third section, while the fourth section explains how this method was used to estimate Hubei's exports, imports and volume of trade. In the subsequent two sections, we assess how well CHARM is able to simulate interregional trade and sectoral supply multipliers. We also decompose the simulation errors into components reflecting the divergence between regional and national technology, final demand and heterogeneity. The penultimate section considers possible ways of enhancing CHARM's performance, while the final section concludes.

\section{THE PROVINCE OF HUBEI}

Hubei is located in central China. It produced around 4.0\% of China's GDP in 2010 and employed about $2.8 \%$ of its urban labour force. ${ }^{1} 44.3 \%$ of Hubei's population resided in urban areas in 2007, a figure that is almost identical to that for China (44.9\%). ${ }^{2}$ Hubei has a diversified economy. The main agricultural products include cotton, rice, wheat and tea, whereas important industries include automobiles, iron and steel, chemicals, construction, food and beverages, machinery and equipment, and textiles. Hubei also produces hightechnology products such as optical electronics and telecommunications. Furthermore, it has significant mineral and forestry resources. ${ }^{3}$

Hubei is traversed by two great rivers, the Yangtze and the Han, which meet in Wuhan, the provincial capital. ${ }^{4}$ The Three Gorges of the Yangtze, which lie to the west of the province, are an important tourist attraction. However, even though hydroelectricity is an important industry in Hubei, the electricity generated is mainly used to supply eastern provinces such as Shanghai, Zhejiang and Jiangsu. Therefore, many coal-fired electricity power stations and heat power plants have been built in several places in Hubei to meet the demand for electricity and heat. Hubei imports coal from Shanxi, Henan and Nei Menggu (Inner Mongolia) to supply these power stations and plants.

Wuhan, which is situated some $1050 \mathrm{~km}$ south of Beijing, is one of China's largest cities (the 2010 census recorded a population of 6.4 million in its urban area and 9.8 million in its administrative area). Wuhan is a major transportation thoroughfare and the city is the economic hub of central China. It is a centre of higher education and research.

The published input-output tables for Hubei and China in 2007 have the same forty-two sectors, which greatly simplifies the analysis. Even so, there are some noticeable differences in how far Hubei and China specialize in particular industries. This diversity is captured in the SLQs displayed in Table 1.5 One can see, for example, that Hubei is highly specialized in sectors such as 1, 6 and 39, whereas sectors 2 and 3 are of negligible importance. However, 
the SLQs do not always tell us the whole story about an industry's regional importance. For instance, the chemical industry, sector 12, accounts for a substantial 5.7\% of Hubei's output, yet its SLQ is well below unity.

\section{Table 1 near here}

\section{CROSS-HAULING AND CHARM}

CHARM is an example of a pure non-survey method, whereby a very limited amount of regional data (such as sectoral employment) is used to regionalize the national input-output table in the initial stages. Although these first steps are entirely mechanical, analysts can subsequently incorporate superior data in an effort to improve their models. Regionalization via the use of location quotients is another example of a pure non-survey approach.

Since CHARM is a refinement of the classical CB approach to constructing a regional input-output table (Isard, 1953), it is appropriate to begin by considering the key concepts underlying the $\mathrm{CB}$ method. At the outset, the analyst would need to use the following formula to estimate the demand for each regional sector:

$$
d t_{i}^{r}=\sum_{j} a_{i j}^{n} x_{j}^{r}+d f_{i}^{r}
$$

where $d t_{i}^{r}$ is total regional demand for commodity $i$ in region $r, a_{i j}^{n}$ is the national technical coefficient (the number of units of commodity $i$, irrespective of source, needed to produce one unit of gross output of national industry $j$ ), $x_{j}^{r}$ is output of regional industry $j, \sum_{j} a_{i j}^{n} x_{j}^{r}$ is intermediate demand, and $d f_{i}^{r}$ is final demand. A key assumption here is that the region and the nation share the same technology. This assumption reflects the fact that data on regional technology are rarely available. Where regional sectoral output is unknown, as is often the case, employment can be used as a proxy.

If $d t_{i}^{r}<x_{i}^{r}$, the entire surplus is assumed to be exported; conversely, if $d t_{i}^{r}>x_{i}^{r}$, it is presumed that sufficient imports will be available to make up for the shortfall in regional output. Cross-hauling is ruled out. The CB method operates on the principle of maximum local trade, i.e. 'if commodity $i$ is available from a local source, it will be purchased from that source' (Harrigan et al., 1981, p. 71). One problem with this principle is that it 'ignores the fact that any industry commodity in practice will be an aggregation of a number of quite distinct commodities' (ibid.), so that cross-hauling is almost bound to occur. Moreover, Richardson (1985, p. 613) remarks that '[a]lthough industrial disaggregation helps to relieve the cross[-]hauling problem, it does not solve it.' Consequently, other explanations of crosshauling need to be explored.

Cross-hauling is ubiquitous in small regions that do not represent a functional economic area (Robison and Miller, 1988) but it is also a serious concern in larger regions (Kronenberg, 2009). It is apt to be encountered in densely populated and highly urbanized countries, especially those where commuting across regional boundaries is important (Boomsma and Oosterhaven, 1992). Kronenberg identifies the heterogeneity of commodities as the main cause of cross-hauling and CHARM represents a novel way of dealing with this problem.

The interregional trade in automobiles between Hubei and other Chinese provinces is a good example of cross-hauling due to product differentiation. For instance, DongfengCitroën cars are shipped from Wuhan, where this company's headquarters is situated, to Shanghai and Beijing, where Shanghai-Volkswagen and Beijing-Hyundai have their headquarters, while Shanghai-Volkswagen and Beijing-Hyundai cars are shipped to Wuhan.

Although product differentiation may well be the primary cause of cross-hauling, we 
should also recognize that many of the forty-two sectors represent an aggregation of several distinct commodities, so that cross-hauling is very likely to occur. Sector 10 exemplifies this point. Suppose that Hubei is an importer of sporting goods but an exporter of paper, printing and stationery; this would create an illusion of cross-hauling, which would vanish if sporting goods were reallocated into a separate sector. Even so, as identical sectoral classifications are used in the tables for China and Hubei, there is no extra heterogeneity from this source.

Let us now compare and contrast CHARM with the CB method. A key similarity is that both methods employ national transaction tables that incorporate imports; this is because they aim to capture the underlying technology of production (Kronenberg, 2012). Also, both employ the concept of a commodity balance; for commodity $i$, this balance, $b_{i}$, is defined as:

$$
b_{i} \equiv e_{i}-m_{i}
$$

where $e_{i}$ and $m_{i}$ denote exports and imports, respectively, and $b_{i}$ represents net exports. The value of $b_{i}$ is computed as the estimated output of commodity $i$ minus the estimated sum of intermediate and domestic final use (Kronenberg, 2009, p. 46). Here the output of each of Hubei's forty-two sectors is given in the official tables and thus does not need to be estimated.

However, while CHARM and the CB method yield identical values for $b_{i}$, they give different values, in general, for the volume of trade, $e_{i}+m_{i}$. This is because CHARM takes cross-hauling, $q_{i}$, explicitly into account via the following equation (ibid., p. 47):

$$
q_{i}=\left(e_{i}+m_{i}\right)-\left|\left(e_{i}-m_{i}\right)\right|
$$

Thus $q_{i}$ will be greater, the larger the volume of trade and the smaller the absolute trade balance. In the CB method, $q_{i}=0$ as $e_{i}>0$ and $m_{i}>0$ cannot, by assumption, occur together. By contrast, with CHARM, $q_{i}>0$ is possible and, indeed, probable in most cases.

For purposes of estimation, Kronenberg posits that $q_{i}$ is proportional to the sum of domestic production, $x_{i}$, intermediate use, $\mathrm{z}_{i}$, and domestic final use, $f_{i}$. The factor of proportionality, $h_{i}$, captures the heterogeneity of commodities, as shown in the equation:

$$
q_{i}=h_{i}\left(x_{i}+\mathrm{z}_{i}+f_{i}\right)
$$

where $0 \leq h_{i}<\infty$ (ibid., p. 51). Consequently, $h_{i}=q_{i} /\left(x_{i}+\mathrm{z}_{i}+f_{i}\right)$, where $q_{i}$ is given by equation (4). Kronenberg assumes that $h_{i}$ is invariant across regions and depends solely on the characteristics of products; it can, therefore, be estimated using national data. (This key assumption is reviewed later in the article.) We would get $h_{i}=0$ if $q_{i}=0$, which would occur if $e_{i}=0$ with $m_{i}>0$ or $m_{i}=0$ with $e_{i}>0$ or $e_{i}=m_{i}=0$.

Table 1 shows that the values of $h_{i}$ based on Chinese national data exhibit considerable diversity. ${ }^{6}$ Six sectors have $h_{i}=0.0000$, indicating the absence of any cross-hauling (indeed, in most cases, any trade). By contrast, manufacturing sectors 19 and 20 show unusually high values of $h_{i}$; this suggests that the products produced in these sectors are very heterogeneous and that there is much cross-hauling. $h_{i}$ is also well above average in other manufacturing sectors such as 12, 16 and 18. Below-average values of $h_{i}$ are found especially in service sectors such as 27, 29 and 31 . Sector 34 has an atypically high value of $h_{i}$ for a service sector but this may reflect the possibility that it is less location-specific than most of the other service sectors. Although the results for China look sensible on the whole, there are many sectors where there are large disparities between the national and regional values of $h_{i}$. This phenomenon is explored in subsequent sections. 


\section{COMMODITY BALANCES, EXPORTS AND IMPORTS}

At the outset, the following formula was employed to estimate the commodity balance (net exports) for each commodity:

$$
\hat{b}_{i}^{r}=x_{i}^{r}-\left(\hat{z}_{i}^{r}+\hat{f}_{i}^{r}+\hat{g}_{i}^{r}\right) \text {, }
$$

where $\hat{b}_{i}^{r}$ is estimated net exports of commodity $i, x_{i}^{r}$ is regional output of this commodity, as shown in the official statistics, $\hat{z}_{i}^{r}$ is the estimated sum of regional intermediate use, $\hat{f}_{i}^{r}$ is estimated regional final use and $\hat{g}_{i}^{r}$ is the estimated residual error.

$\hat{z}_{i}^{r}$ was calculated using the formula:

$$
\hat{z}_{i}^{r}=\sum_{j} \hat{z}_{i j}^{r}=\sum_{j}\left(a_{i j}^{n} \times x_{j}^{r}\right)
$$

where $\hat{z}_{i j}^{r}$ is the estimated value of intermediate inputs of commodity $i$ needed by industry $j$ in Hubei, $a_{i j}^{n}$ is the national technical coefficient and $x_{j}^{r}$ is the output of regional industry $j$. It was assumed that Hubei and China shared the same technology. The values of $\hat{f}_{i}^{r}$ and $\hat{g}_{i}^{r}$ were calculated by scaling down the respective national values using the formulae:

$$
\begin{aligned}
\hat{f}_{i}^{r} & =\left(\sum_{i} x_{i}^{r} / \sum_{i} x_{i}^{n}\right) \times f_{i}^{n}, \\
\hat{g}_{i}^{r} & =\left(\sum_{i} x_{i}^{r} / \sum_{i} x_{i}^{n}\right) \times g_{i}^{n},
\end{aligned}
$$

where $\sum_{i} x_{i}^{r} / \sum_{i} x_{i}^{n}$ is the ratio of total regional to total national output. This proportional scaling is a very common approach, which is dictated by the lack of more refined data in most cases. Its appropriateness is explored later in this paper.

Equation (5) is all that is needed for the CB method, which does not give separate estimates of exports and imports, and presumes that the volume of trade is equal to the absolute trade balance. However, with CHARM, some further manipulations are required in order to take cross-hauling into account (cf. Kronenberg, 2009, p. 50). The first step is to rearrange equation (3) to solve for the volume of trade, $v_{i}$ :

$$
v_{i} \equiv e_{i}+m_{i}=\left|b_{i}\right|+q_{i},
$$

where $b_{i}$ (net exports) can be estimated via equation (5). For $q_{i}$ (cross-hauling), we use:

$$
\hat{q}_{i}^{r}=h_{i}^{n}\left(x_{i}^{r}+\hat{z}_{i}^{r}+\hat{f}_{i}^{r}+\hat{g}_{i}^{r}\right)
$$

where $h_{i}^{n}$ is the measure of heterogeneity of commodities (based on national data). Finally, we need to rearrange equation (9) to get expressions for regional exports and imports:

$$
\begin{gathered}
e_{i}=1 / 2\left(v_{i}+b_{i}\right), \\
m_{i}=1 / 2\left(v_{i}-b_{i}\right) .
\end{gathered}
$$

We can now estimate Hubei's exports and imports separately, along with its volume of trade. 


\section{ESTIMATING HUBEI'S IMPORTS AND EXPORTS}

Table 2 highlights the differences between CHARM and the CB method. A key point is that, with the latter, a positive trade balance, $b_{i}>0$, yields a corresponding volume of exports but no imports. Conversely, a negative trade balance, $b_{i}<0$, generates an equivalent amount of imports but no exports. Cross-hauling is precluded by the CB procedure, whereas CHARM takes this common characteristic of regional trade explicitly into account, which is why it yields a greater volume of both exports and imports. This outcome, which is in accordance with the Finnish findings of Flegg and Tohmo (2013a), can be verified from Table 2, where the column sums show that aggregate exports and imports are, respectively, 32\% and 50\% higher with CHARM. It is also worth noting that the CB method suggests that twenty-five of the forty-two sectors did not import any of their inputs, whereas CHARM finds only five such cases. As regards exports, the CB method classifies seventeen sectors as non-exporters, whereas CHARM identifies only one such case. By comparison, the official data record eight non-exporting and seven non-importing sectors.

\section{Table 2 near here}

Nevertheless, an intriguing facet of the results in Table 2 is the unexpectedly high volume of trade generated by the CB method: estimated imports are $82 \%$ of the official figure, while estimated exports are overstated by $22 \%$. Consequently, the estimated volume of trade is $2.6 \%$ above the benchmark. This is a surprising outcome for a method that precludes cross-hauling but it can be explained by the errors introduced by using national data to measure technology and the pattern of final demand, as discussed below.

Another interesting aspect of the results in Table 2 is that aggregate imports and exports from CHARM are well above the official figures (61\% higher for exports and $23 \%$ higher for imports). In order to explain these discrepancies, it is helpful to decompose the overall error into three components:

- a scaling error due to the use of scaled national data to estimate regional final demand, $f_{i}$, and the residual error, $g_{i}$;

- a technology error introduced via the use of national data to estimate regional intermediate transactions, $z_{i}$;

- a heterogeneity error brought about by using national data to measure the degree of heterogeneity of products, $h_{i}$.

\section{Table 3 near here}

From the column sums in Table 3, we can separate out the contribution of each type of error to the overall error. For imports, this process gives:

- $\quad$ scaling error $=347,775-438,138=-90,363$

- $\quad$ technology error $=438,138-206,145=231,993$

- heterogeneity error $=206,145-282,474=-76,329$

- $\quad$ overall error $=347,775-282,474=65,301$

The corresponding figures for exports are:

- $\quad$ scaling error $=478,459-305,340=173,119$

- technology error $=305,340-220,461=84,879$

- heterogeneity error $=220,461-296,790=-76,329$

- $\quad$ overall error $=478,459-296,790=181,669$

The first point to note is that the heterogeneity error is identical for exports and imports; this error depends solely on the extent to which $h_{i}^{r}$ and $h_{i}^{n}$ diverge. It is evident that the key 
reason for CHARM's better overall performance in terms of imports is that the scaling error partly offsets the technology error, whereas these two types of error reinforce each other for exports. It is interesting that, for imports, technology errors are more serious than scaling errors, whereas the converse is true for exports. It is also worth noting that the heterogeneity error is the smallest of the three types of error.

Let us now examine some specific results for imports. In many cases, CHARM's estimates of imported manufactured goods far exceed the official figures, although the massive shortfall in sector 6 is a striking exception to this pattern. A less extreme shortfall occurs in sector 17. Outside of manufacturing, it is noticeable how CHARM yields absurdly low imports for sector 1 , while the only anomalous services sector is 34 , where CHARM greatly overstates regional imports.

Table 3 shows the results of using the official regional figures for $f_{i}$ and $g_{i}$ in place of estimates derived by applying formulae (7) and (8) to scale the national data. The net effect of this change is to raise estimated imports by $26 \%$, from 347,775 to 438,138 million yuan. However, over half of this rise can be traced to sectors 6 and 17. The initial shortfall in imports is largely due to an understatement of final consumption in sector 6 and of gross fixed capital formation in both sectors. Issues of this kind are taken up in the penultimate section of this paper. The use of official data has a big impact in sector 34, cutting its estimated imports by about $25 \%$. Other sectors with pronounced scaling errors include 9,10 , 29 and 31. As expected, scaling errors are negligible for the primary sectors 1 to 5.

Regarding technology errors, Table 3 reveals that the use of official regional intermediate transactions data causes a marked fall in the estimated imports for most manufacturing sectors. Indeed, the upshot of switching from national to regional technology is that aggregate estimated imports fall by $53 \%$, from 438,138 to 206,145 million yuan. This outcome reflects the fact that most sectors in Hubei are more efficient than those in China as a whole, in the sense that they have a lower ratio of intermediate inputs to output. This greater efficiency means that the typical Hubei industry has a lower propensity to import.

The facility to allow for the impact of heterogeneity of products on regional trade is the unique contribution of CHARM, so it is worth exploring this aspect. To do so, it is helpful to substitute equation (9) into (12), so that:

$$
m_{i}=1 / 2\left(\left|b_{i}\right|+q_{i}-b_{i}\right)
$$

which gives $m_{i}=1 / 2 q_{i}$ for $b_{i}>0$ and $m_{i}=1 / 2 q_{i}+\left|b_{i}\right|$ for $b_{i}<0$, where $b_{i} \equiv e_{i}-m_{i}$. Similarly, by substituting equation (9) into (11), we get:

$$
e_{i}=1 / 2\left(\left|b_{i}\right|+q_{i}+b_{i}\right)
$$

which gives $e_{i}=1 / 2 q_{i}$ for $b_{i}<0$ and $e_{i}=1 / 2 q_{i}+b_{i}$ for $b_{i}>0$. Thus both imports and exports are increasing functions of cross-hauling, $q_{i}$. Also, depending on whether there is a trade deficit $\left(b_{i}<0\right)$ or surplus $\left(b_{i}>0\right), m_{i}$ and $e_{i}$ also vary with the trade balance. At this stage, however, since we have eliminated both scaling and technology errors, there is no need to consider errors in $b_{i}$ as a possible source of errors in $m_{i}$ and $e_{i}$.

Now let us re-examine the anomalous sector 1 . Since $b_{i}>0$, the equation $m_{i}=1 / 2 q_{i}$ applies, so CHARM's unrealistically low figure for imports must be due to an underestimation of cross-hauling. To demonstrate this, consider the following variant of equation (10), where the estimates of $z_{i}, f_{i}$ and $g_{i}$ have been replaced by official Hubei data:

$$
q_{i}=h_{i}\left(x_{i}+z_{i}+f_{i}+g_{i}\right)
$$


For sector 1, Table 2 gives $x_{i}=230,478$, while $z_{i}+f_{i}+g_{i}=x_{i}-b_{i}=228,621$. If we retain CHARM's assumption of identical regional and national heterogeneity, so that $h_{i}=0.0134$ (see Table 1), we get $q_{i}=0.0134 \times 459,099 \approx 6,152$ and $m_{i}=0.5 \times 6,152=3,076$. Rounding errors aside, this figure for estimated imports confirms the one given in Table 3 . The outcome changes dramatically, however, if we use $h_{i}^{r}=0.1603$ instead of $h_{i}^{n}=0.0134$ (again see Table 1). This region-specific value of $h_{i}$ yields $q_{i}=0.1603 \times 459,099 \approx 73,594$, so that $m_{i}=0.5 \times 73,594=36,797$, which accords with the official imports for sector 1 .

Sector 6 is another instance where Table 3 records a massive heterogeneity error. However, when a more realistic figure for $h_{i}$ is used, namely $h_{i}^{r}=0.1723$ rather than $h_{i}^{n}=0.0380$, estimated imports rise sharply from 6,599 to 29,921 million yuan, the official value. This sector is unusual since Table 3 also reveals huge scaling and technology errors, yet these errors largely offset each other, so the heterogeneity error essentially determines the overall result. A similar outcome occurs in sector 1 but for a different reason: here the scaling and technology errors are negligible and hence hardly affect the overall error.

By contrast, for sector 19, CHARM's estimate of imports is 25,743 million yuan above the official figure. This huge gap is due to a scaling error of $-9,696$, a technology error of 24,017 and a heterogeneity error of 11,421. Unlike the previous two examples, however, the heterogeneity error is positive, which reflects the fact that $h_{i}^{n}=0.4217$, while $h_{i}^{r}=0.1571$.

Let us now consider CHARM's estimates of exports. Here it is helpful to split the data into two broad groups: sectors 1-22 and 23-42. This dichotomy reflects the fact that, for the first group, CHARM yields smaller overall errors for exports than for imports for seventeen of the twenty-two sectors. For instance, for sector 6 , the overall error is 6,110 for exports but $-23,892$ for imports. By contrast, for the second group, the results are worse for exports in sixteen cases out of twenty. Table 1 shows that this second group spans sectors such as energy, construction, transport and storage, wholesale and retail, hotels, education and public management, whereas the first group is focused on agriculture and manufacturing.

It is striking that CHARM misses the large volume of exports officially recorded for sector 23. As noted in Section 2, Hubei exports much of its electricity to other provinces and CHARM signally fails to capture this aspect. Table 3 shows very big technology and heterogeneity errors for this sector. By contrast, CHARM greatly overstates the exports of sector 30, owing to large errors of all three types. Furthermore, the official statistics show zero or negligible exports for sectors 26, 33, 39 and 42, yet CHARM indicates substantial exports in each case. These are all regionally based sectors for which one would not expect significant exports. Table 3 records big scaling as well as technology errors for sectors 26, 33 and 39, whereas the problem for sector 42 is almost wholly a scaling issue.

From the above discussion, it is obvious that CHARM's estimates of exports and imports for individual sectors should be treated with the utmost caution. Its estimates of the exports of the energy, construction and services sectors are especially unreliable. The primary cause of the poor simulations is the difficulty of getting reliable regional data for final demand, intermediate transactions and the degree of heterogeneity of products. Possible ways round this problem are explored in the penultimate section of the article.

\section{ESTIMATING SUPPLY MULTIPLIERS FOR HUBEI}

A multiplier is an invaluable tool for evaluating the impact of fluctuations in the demand for the product of a particular regional sector. Indeed, regional analysts may be more interested in obtaining satisfactory estimates of sectoral multipliers than in estimating regional exports and imports. In this study, supply rather than output multipliers have been computed (Kronenberg, 2012). Supply multipliers measure the impact of changes in final demand on 
the total supply of commodities rather than on regional output. They are, therefore, useful in environmental assessments, where the focus is on the total supply of a pollutant rather than on where it was produced. A good example here is the coal imported by Hubei to supply its coal-fired power stations and power plants, as mentioned earlier.

The supply multipliers were computed as follows. First, the supply of each industry $j$ was calculated by summing the regional output of $j, x_{j}$, and the imports of this product, $m_{j}$. Secondly, a set of supply-based regional input coefficients was defined as:

$$
r_{i j}^{s}=z_{i j} /\left(x_{j}+m_{j}\right),
$$

where $z_{i j}$ is the total value of intermediate inputs purchased by industry $j$ from sector $i$, inclusive of goods sourced from within Hubei, from other provinces or from abroad. The coefficient matrix corresponding to equation (16) can be written as $\mathbf{R}^{\mathbf{s}}=\left[r_{i j}^{s}\right]$. Thirdly, the Leontief inverse of $\mathbf{R}^{\mathbf{s}}$ was derived. This can be expressed as $\mathbf{L}^{\mathbf{s}}=\left[b_{i j}^{s}\right]$. Lastly, each column of $\mathbf{L}^{\mathbf{s}}$ was summed to obtain the sectoral supply multiplier, $k_{j}$ :

$$
k_{j}=\sum_{i} b_{i j}^{s}
$$

The results from each method and the official data are displayed in Table 4.

\section{Table 4 near here}

The official data yield a mean supply multiplier of 1.919. This figure suggests that a rise in the final demand for Hubei's industries of one million yuan would raise the total supply of commodities (including products imported from other provinces or from abroad) by 1.919 million yuan on average. CHARM indicates a somewhat higher average rise of 2.078 million, whereas the $\mathrm{CB}$ method signals a rise of 2.218 million.

The fact that the $\mathrm{CB}$ method invariably produces bigger supply multipliers than CHARM can easily be explained in terms of equation (16): the two methods use identical values for $z_{i j}$ and $x_{j}$ but different values for $m_{j}$. CHARM produces higher imports because it encompasses heterogeneity and thus cross-hauling. Hence the input coefficients and thus supply multipliers from CHARM are lower than those from the CB method. ${ }^{7}$

The disparity between the estimated multipliers from CHARM and the CB method also varies across sectors. This divergence is small for sectors producing relatively homogeneous products, where cross-hauling is apt to be insignificant, such as sector 15 . Big differences occur in sectors such as 19 and 20, which have very high values of $h_{i}$ and hence exhibit much cross-hauling, especially at the national level (see Table 1). Sectors 2, 3 and 22 are unusual as both methods give multipliers close to the minimum of $k_{j}=1$; this arises because each sector produces a mere $0.1 \%$ of Hubei's total output (see Table 1), so intermediate transactions are negligible and a very high proportion of supply comes from other regions. ${ }^{\mathbf{8}}$

Table 4 reveals that the mean multiplier based on official Hubei data is somewhat lower than CHARM's estimate. This finding can once again be explained in terms of scaling, technology and heterogeneity errors; on average, these errors cause the multipliers from CHARM to be overstated by $0.066,0.072$ and 0.022 , respectively.

The scaling error operates via the term $m_{j}$ in equation (16). This error is positive for all but six Hubei sectors, so it tends to lower $m_{j}$ for the typical sector and thereby boost $k_{j}$. To illustrate, Table 3 shows that CHARM's original estimate of imports for sector 6 is 6,029 million yuan, yet when the official Hubei data for final demand and the residual error are 
used, estimated imports rise to 23,802 million. Table 4 records a scaling error of 0.194 , so the extra imports reduce the estimated supply multiplier from 2.529 to 2.335 . The result in sector 17 is even more striking: imports rise from 8,536 to 39,327 million yuan and the multiplier falls from 2.771 to 2.216. These two sectors are, however, rather unusual in terms of the size of their scaling errors.

The technology error operates in a more complex way than the scaling error, as it affects both $z_{i j}$ and $m_{j}$ in equation (16). Here we should note that the multipliers from CHARM and those based on the official Hubei statistics use identical values for $x_{j}$ but different values, in general, for both $z_{i j}$ and $m_{j}$. As regards $z_{i j}$, it is helpful to examine the ratio $\sum_{i} z_{i j} / x_{j}$, which represents the degree of intermediation. With CHARM, the $z_{i j}$ were calculated using the national technical coefficients and hence reflect the national technology, whereas the official tables for Hubei reflect technology specific to this province. In fact, for thirty-four of the forty-two sectors, CHARM gives higher values for $\sum_{i} z_{i j} / x_{j}$. On average, this ratio is 0.619 for CHARM but 0.553 for the official data. This disparity is a key reason why the multipliers from CHARM exceed those based on the official data.

To assess the impact of technological differences, the multipliers were recalculated by using official data for intermediate inputs instead of data derived by multiplying the known output of each sector by the corresponding national technical coefficient. This substitution affected the multipliers directly via the term $z_{i j}$ in equation (16) and caused the mean multiplier to fall from 2.078 to 1.823 . This fall reflects the fact that Hubei's industries are typically more economical in their use of intermediate inputs than those in China as a whole.

However, with CHARM, the term $z_{i j}$ indirectly affects the size of the supply multipliers via its effect on $m_{j}$ in equation (16). Imports are affected because a change in $z_{i j}$ alters the estimated trade balance $\hat{b}_{i}^{r}$ in equation (5) and the estimate of cross-hauling $\hat{q}_{i}^{r}$ in equation (10). When these indirect effects were taken into account, estimated imports fell and the mean multiplier rose from 1.823 to 1.941 .

By adding the direct and indirect effects of using the official regional transactions data, we get the technology effect shown in Table 4. Although this effect only slightly exceeds the scaling effect on average, the averaging masks the fact that the nineteen negative values go a long way towards offsetting the twenty-three positive ones. Indeed, when absolute values are taken, the mean technology error rises from 0.072 to 0.167 . Moreover, many of the individual errors have a big impact on the estimated multipliers. For instance, those for sectors 15 and 39 are overstated by 0.350 and 0.302 , respectively. By contrast, the technology error is small for some key sectors such as 1, 6, 17 and 26. In general, however, CHARM's use of national technical coefficients greatly impairs the accuracy of its estimates of sectoral supply multipliers.

Finally, we should explore the effects of employing regional rather than national data to capture the heterogeneity of commodities (see Table 1). Using $h_{i}^{r}$ in equation (10) when estimating cross-hauling boosts imports and hence supply for the average sector; this, in turn, slightly lowers the mean multiplier from 1.941 to 1.919 , which is the expected value when all three sources of error are removed. There is little overall impact since nineteen sectors have $h_{i}^{n}>h_{i}^{r}$, nineteen have $h_{i}^{n}<h_{i}^{r}$, and four have $h_{i}^{n}=h_{i}^{r}=0$. Hence the means are very close, 0.0696 for $h_{i}^{r}$ and 0.0606 for $h_{i}^{n}$, while the mean heterogeneity error is only 0.022 . However, this unremarkable overall outcome masks some fairly big differences in particular sectors, which reflect divergent values of $h_{i}^{n}$ and $h_{i}^{r}$. For instance, for sector 20, $h_{i}^{n}=0.6195$ gives $k_{j}=1.645$, whereas $h_{i}^{r}=0.2349$ yields $k_{j}=1.834$. When absolute values are taken, the mean heterogeneity error rises from 0.022 to 0.059 , although this is still well 
below the mean absolute technology error of 0.167 .

\section{ENHANCING CHARM'S PERFORMANCE}

The disappointing results from CHARM suggest that we should explore ways of enhancing its performance. The earlier discussion highlighted three key weaknesses: (i) the use of national technical coefficients to represent regional technology; (ii) the errors in scaling final demand; and (iii) the use of national data to measure the heterogeneity of commodities.

A key obstacle encountered when estimating imports, exports and supply multipliers was that the national technical coefficients did not accurately portray the technical requirements of Hubei's industries, leading to inaccurate estimates of intermediate demand. Productivity in Hubei generally exceeds that in China as a whole, which means that its technical coefficients tend to be smaller than the corresponding national ones. This means, of course, that the proportion of value added - primarily labour costs and profits - tends to be higher in Hubei than in China as a whole. This problem can be addressed, in principle at least, by using Round's 'fabrication' factor (Round, 1972, p. 6).

Round's approach can be implemented via the following formula:

$$
a_{i j}^{r}=\frac{1-\left(w_{j}^{r} / x_{j}^{r}\right)}{1-\left(w_{j}^{n} / x_{j}^{n}\right)} a_{i j}^{n},
$$

where $w$ denotes value added and $x$ denotes gross output (cf. Miller and Blair, 2009, pp. 356-357). To illustrate, consider sector 20, where $w_{j}^{r} / x_{j}^{r}=0.3055$ but $w_{j}^{n} / x_{j}^{n}=0.2116$. Thus $a_{i j}^{r}=0.881 \times a_{i j}^{n}$, so that the national technical coefficients in column 20 of Hubei's matrix would need to be scaled down by a common factor of 0.881 , i.e. reduced by $11.9 \%$, to reflect the more economical use of intermediate inputs by sector 20 in Hubei relative to China as a whole. In equation (6), $a_{i j}^{n}$ would need to be replaced by $a_{i j}^{r}$. Such adjustments are easy to implement but they presuppose that the analyst is aware of which regional industries diverge significantly from the national value-added ratios and by how much. ${ }^{9}$

The ratio of total regional to total national output was used to scale national final demand and we now need to consider whether this method could be refined. A possibility in China is to use the ratio of total regional to total national consumption to scale consumption, while retaining the output ratio for the other parts of final demand. These ratios are 0.0379 and 0.0271, respectively, for Hubei. This fresh approach worked well: it cut the overall scaling error for imports from $-90,363$ to $-60,798$ million yuan or, relatively speaking, from $-20.6 \%$ to $-13.9 \%$ (see Table 3 ). The sectors most affected included 6, 17 and 29.

CHARM assumes that each region has the same pattern of consumption as the nation, so one might ask how realistic this assumption is for Hubei. To explore this issue, the regional sectoral consumption shares were regressed on the corresponding national shares. The resulting equation, $\hat{c}_{i}^{r}=-0.003+1.109 c_{i}^{n}$, with $R^{2}=0.817$ and $t$ ratios of -0.78 and 13.35, suggests that it is not unreasonable to assume an identical pattern of consumption. Similarly, the regional sectoral ratios of gross fixed capital formation to output were regressed on the corresponding national ratios. The resulting equation, $\hat{g}_{i}^{r}=0.006+0.753 g_{i}^{n}$, with $R^{2}=0.904$ and $t$ ratios of 1.74 and 19.37, indicates a strong relationship between the regional and national ratios, albeit with some deviation from a $45^{\circ}$ line. Taken together, these results offer some support for the refined scaling approach proposed above. ${ }^{\mathbf{1 0}}$

A final source of error was the use of national data to measure the heterogeneity of 
commodities. Kronenberg (2009, p. 51) justifies the assumption $h_{i}^{r}=h_{i}^{n}$ on the grounds that 'the heterogeneity of commodity $i$ is the same in the region as in the nation', which he says is reasonable 'because product heterogeneity is a characteristic of the commodity, not of a specific geographical location.' While it may well be reasonable to assume that regional and national products exhibit the same degree of heterogeneity, what is more contentious is whether the mix of products in regional and national sectors is sufficiently similar to warrant setting $h_{i}^{r}=h_{i}^{n}$. Jackson (2014) argues, for instance, that this mix is bound to vary across regions; one obvious reason is that not every product included in a national sector would be produced everywhere. He also cites regional differences in tastes and preferences, along with differences in the economic size of regions, as reasons why $h_{i}^{r}$ and $h_{i}^{n}$ are likely to diverge.

Nevertheless, Kronenberg's assumption does appear to be a reasonable starting point in the case of Hubei. As noted previously, based on official data, the means are very close, 0.0696 for $h_{i}^{r}$ and 0.0606 for $h_{i}^{n}$, while the mean heterogeneity error is only 0.022 for the supply multipliers. However, some large errors occurred in particular sectors, for which differences in product mix might be a key explanation. Therefore, national sectors should be scrutinized to see whether their composition is realistic for the region under study. The values of $h_{i}$ could then be refined if necessary.

A final way of enhancing CHARM's performance would be to pursue a hybrid approach, which aims 'to strike a balance between the accuracy of [a regional input-output] table and the cost of constructing it' (Kronenberg, 2009, p. 52). Indeed, Kronenberg advocates the use of just such a strategy; more specifically, he recommends making judicious use of superior data from official sources and partial surveys. For instance, analysts might be able to obtain disaggregated data on regional consumption by households, which could be used to improve the estimates of final demand. Also, partial surveys could be carried out of key sectors and important cells in the regional input-output table. Furthermore, Lahr (1993) stresses the importance of obtaining superior data for households and for establishments in resourcebased and 'miscellaneous' sectors. He singles out agriculture and the extractive industries as cases where a divergence between regional and national technology is very likely to occur.

\section{CONCLUSION}

This article has employed official data for the Chinese province of Hubei to assess the performance of Kronenberg's CHARM, a new method designed to take explicit account of cross-hauling when constructing regional input-output tables. By adjusting the Chinese national tables, CHARM was used to simulate the input-output structure of Hubei.

At the outset, Kronenberg's procedure was adopted to measure the degree of heterogeneity, $h_{i}$, of forty-two separate commodities, using Chinese national data. These values of $h_{i}$ were then used to adjust for cross-hauling and to estimate Hubei's sectoral imports, exports and volume of trade. However, the estimates obtained were often highly unrealistic. Furthermore, CHARM overstated Hubei's total imports by 65,301 million yuan and its total exports by 181,669 million. ${ }^{11}$

Three sources of error in CHARM's estimates of regional trade were identified via a decomposition analysis. These scaling, technology and heterogeneity errors refer to errors introduced by (i) using scaled national data to estimate regional final demand; (ii) adopting national rather than regional technology; and (iii) using national rather than regional values of $h_{i}$. In the case of imports, these errors amounted to $-90,363,231,993$ and $-76,329$ million yuan, respectively. By contrast, for exports, the scaling and technology errors were 173,119 and 84,879 million, respectively, while the heterogeneity error was as before. It is worth noting that the heterogeneity error is the smallest of the three types of error. 
Although CHARM clearly failed to measure Hubei's volume and pattern of trade satisfactorily, its estimates of supply multipliers were generally more realistic. These multipliers suggested that, on average, a rise in the final demand for Hubei's industries of one million yuan would raise the total supply of commodities (including products imported from other provinces or from abroad) by 2.078 million yuan. Since the official data indicated an average rise of 1.919 million yuan, this represents an average overstatement of 0.159 , made up of scaling, technology and heterogeneity errors of $0.066,0.072$ and 0.022 , respectively. By contrast, the classical CB method overstated the multipliers by 0.299 on average. This overstatement is bigger because the $\mathrm{CB}$ method tends to understate imports, as it disregards the heterogeneity of commodities and hence cross-hauling.

We identified four key ways in which CHARM's performance might be enhanced. The first was to use Round's 'fabrication' factor to adjust for any known divergence between regional and national technology. Secondly, we investigated some alternative ways of scaling national final demand. This investigation highlighted the importance of scaling final consumption correctly. Thirdly, we examined possible reasons why the national and regional values of $h_{i}$ might diverge. Here we recommended that adjustments should be made to allow for any known differences between the sectoral mix of products at the regional and national levels. Lastly, it was suggested that a hybrid approach could be pursued, with judicious use being made of superior data gleaned from official sources and from partial surveys of key regional sectors and important cells in the regional input-output table.

Nonetheless, some basic issues remain to be addressed concerning Kronenberg's assumption that $h_{i}^{r}=h_{i}^{n}$. For instance, the heterogeneity of products traded internationally might differ from that in interregional trade. More fundamentally, Jackson (2014) suggests that Kronenberg's formula for estimating cross-hauling is mis-specified in the sense that it presumes that the share of cross-hauling (as measured by $h_{i}$ ) is invariant across regions. Jackson argues that this share should vary with a region's economic size. However, the evidence presented here for Hubei suggests that Kronenberg's assumption does not yield systematically incorrect results. Clearly, this issue requires further investigation. In particular, it would be instructive to investigate what happens to interregional and international trade as regions get larger and the impact this has on the values of $h_{i}$.

The results presented here for Hubei differ markedly from those obtained by Flegg and Tohmo (2013a) for Uusimaa in Finland, where CHARM gave reasonable estimates of the volume and pattern of trade. A key reason for this dissimilarity is probably that Uusimaa is a relatively large province, which produced $34.6 \%$ of Finland's national output in 2002, and accounted for $31.4 \%$ of total employment, whereas Hubei produced around $4 \%$ of China's GDP in 2010 and employed about $2.8 \%$ of its urban labour force. Furthermore, the sheer geographical size of China is likely to pose problems in any simulation of regional trade.

Indeed, there are good reasons to expect CHARM to perform better in relatively large regions than in relatively small ones. In particular, regional and national technology should converge as regional size increases simply because a greater proportion of national production would occur within the region. For similar reasons, the pattern of regional final demand should converge to the national one as regions get larger. Our findings for Hubei serve to emphasize the importance, especially in smaller regions, of adjusting for any known differences in technology and the pattern of final demand. As with any pure non-survey technique, CHARM can only be expected to produce an initial set of results, which should then be reviewed by the analyst and suitable adjustments made. At best, CHARM can only be expected to attain 'holistic' accuracy (Jensen, 1980).

It is worth emphasizing that CHARM is suitable for environmental and other applications where the focus is on the overall supply of goods, regardless of their source. It can only be used in conjunction with type A national tables, where intermediate transactions 
include imports. By contrast, where the focus is on regional output and employment, the FLQ (Flegg's location quotient) may be used to generate an initial set of regional input coefficients. ${ }^{12}$ However, it requires national transactions matrices that exclude imports (type B tables), which are unavailable for China. ${ }^{\mathbf{1 3}}$

\section{Footnotes}

1. Source: National Bureau of Statistics of China (2011a).

2. Source: National Bureau of Statistics of China (2009).

3. For more detail on Hubei's economy, see Hubei Bureau of Statistics (2011).

4. However, this geographic feature has little effect on Hubei's trading patterns. The Han is mostly used for intra-provincial transportation owing to its limited navigational capacity. Also, cargoes exported by upstream provinces only pass through Hubei along the Yangtze if carried on ships and this activity would not be recorded in Hubei's exports.

5. The SLQs were computed using the equation:

$$
S L Q_{i} \equiv \frac{x_{i}^{r} / \sum_{i} x_{i}^{r}}{x_{i}^{n} / \sum_{i} x_{i}^{n}} \equiv \frac{x_{i}^{r}}{x_{i}^{n}} \times \frac{\sum_{i} x_{i}^{n}}{\sum_{i} x_{i}^{r}},
$$

where $x_{i}^{r}$ is regional output in sector $i$ and $x_{i}^{n}$ is the corresponding national figure. $\sum_{i} x_{i}^{r}$ and $\sum_{i} x_{i}^{n}$ are the respective regional and national totals.

6. For the calculations, the formula was modified to $h_{i}=q_{i} /\left(x_{i}+\mathrm{z}_{i}+f_{i}+g_{i}\right)$, where $g_{i}$ is the residual error, which arises because national output is unequal to total domestic intermediate and final demand plus net exports or, symbolically, $x_{i} \neq \mathrm{z}_{i}+f_{i}+\left(e_{i}-m_{i}\right)$. To illustrate, consider sector 12 , where $q_{i}=1,447,584, x_{i}=6,199,809, z_{i}=6,156,694, f_{i}=284,330$ and $g_{i}=-54,490$, which gives $h_{i}=0.1150$. For Hubei in 2007, the official data show an overall residual error equal to $1.2 \%$ of total output.

7. CHARM and the CB method would produce identical output multipliers because the term $z_{i j}$ in equation (16) would be the same and $m_{j}$ would not be present.

8. According to the official statistics, the ratio $\sum_{i} z_{i j} /\left(x_{j}+m_{j}\right)$ equalled $0.078,0.054$ and 0.139 , respectively, for sectors 2, 3 and 22. CHARM gave figures of $0.069,0.026$ and 0.049 . Hence it is unsurprising that the multipliers for these sectors are very low.

9. For an application of this approach, using data for Mecklenburg-Western Pomerania, see Kronenberg (2010). Data to inform such assessments can be gleaned from many sources. For instance, in Germany, value added is reported annually for the federal states disaggregated into 16 sectors. In Finland, regional accounts are published annually and are a source of value-added data. Regarding the USA, Lahr (2001, p. 172) remarks that 'The US Bureau of Economic Analysis, which releases the official US I-O tables, produces a series on value added for states, albeit at a rather aggregated level both geographically and sectorally.'

10. As another experiment, final consumption was scaled by the ratio of total regional to total national consumption, while sectoral output shares were used for the remaining components. However, this method gave decidedly worse results for manufacturing sectors 16, 18 and 19, along with similar results for most of the remaining sectors.

11. It should be noted that the official statistics used in this evaluation of CHARM are bound to contain errors, yet their extent is unfortunately impossible to ascertain with any precision. Nevertheless, in the authors' considered opinion, the official figures for Hubei's exports and imports appear to be questionable in the following instances:

Sector 1: the recorded figure for net exports of 1,857 million yuan looks rather low.

Sectors 17 and 28: there should arguably be positive rather than negative trade balances.

Sector 24: there should arguably be a negative rather than a positive trade balance.

12. See Bonfiglio and Chelli, 2008; Flegg et al., 1995; Flegg and Tohmo, 2013b, 2014; Flegg and Webber, 1997, 2000; Kowalewski, 2015; Tohmo, 2004. 
13. This taxonomy of tables into types A and B follows Kronenberg (2012) and the United Nations (1973). It is possible, however, to make some crude adjustments for 'competitive' imports and thereby convert a type A national transactions table into an approximation of a type B table; see Miller and Blair (2009, pp. 149-157).

\section{Acknowledgements}

The authors wish to thank the anonymous referees for their detailed and perceptive comments, which led to substantial improvements in this article. They also wish to thank Randall Jackson, Tobias Kronenberg and Chris Webber for helpful suggestions. Yongming Huang's research was supported by Chinese National Social Science Grant 13BJL049 and Social Science Grant of Ministry of Education 12YJA790054; and Timo Tohmo's research by Academy of Finland project 251071.

\section{References}

Bonfiglio, A. and F. Chelli (2008) Assessing the behaviour of non-survey methods for constructing regional input-output tables through Monte Carlo simulation. Economic Systems Research, 20, $243-258$.

Boomsma, P. and J. Oosterhaven (1992) A double-entry method for the construction of bi-regional input-output tables. Journal of Regional Science, 32, 269-284.

Flegg, A.T. and T. Tohmo (2013a) A comment on Tobias Kronenberg's "Construction of regional input-output tables using nonsurvey methods: the role of cross-hauling". International Regional Science Review, 36, 235-257, first published on 13 June 2012 (OnLine First), doi: $10.1177 / 0160017612446371$.

Flegg, A.T. and T. Tohmo (2013b) Regional input-output tables and the FLQ formula: a case study of Finland. Regional Studies, 47, 703-721, first published on 25 August 2011 (iFirst), doi:10.1080/00343404.2011.592138.

Flegg, A.T. and T. Tohmo (2014) Estimating regional input coefficients and multipliers: the use of FLQ is not a gamble. Regional Studies, first published on 30 May 2014, http://www.tandfonline.com/doi/full/10.1080/00343404.2014.901499.

Flegg, A.T. and C.D. Webber (1997) On the appropriate use of location quotients in generating regional input-output tables: reply. Regional Studies, 31, 795-805.

Flegg, A.T. and C.D. Webber (2000) Regional size, regional specialization and the FLQ formula. Regional Studies, 34, 563-569.

Flegg, A.T., C.D. Webber and M.V. Elliott (1995) On the appropriate use of location quotients in generating regional input-output tables. Regional Studies, 29, 547-561.

Harrigan, F., J.W. McGilvray and I.H. McNicoll (1981) The estimation of interregional trade flows. Journal of Regional Science, 21, 65-78.

Hubei Bureau of Statistics (2011) Hubei Statistical Yearbook 2011. China Statistics Press, Beijing.

Isard, W. (1953) Regional commodity balances and interregional commodity flows. American Economic Review Papers and Proceedings, 43, 167-180.

Jackson, R.W. (1998) Regionalizing national commodity-by-industry accounts. Economic Systems Research, 10, 223-238.

Jackson, R.W. (2014) Cross-hauling in input-output tables: comments on CHARM. Working Paper 2014-02, Regional Research Institute, West Virginia University, rri.wvu.edu.

Jensen, R.C. (1980) The concept of accuracy in regional input-output models. International Regional Science Review, 5, 139-154.

Kowalewski, J. (2015) Regionalization of national input-output tables: empirical evidence on the use of the FLQ formula. Regional Studies, 240-250, first published on 25 February 2013 (iFirst), doi:10.1080/00343404.2013.766318.

Kronenberg, T. (2009) Construction of regional input-output tables using nonsurvey methods: the role of cross-hauling. International Regional Science Review, 32, 40-64. 
Kronenberg, T. (2010) Erstellung einer input-output-tabelle für Mecklenburg-Vorpommern. AStA Wirtschafts- und Sozialstatistisches Archiv, 4, 223-248.

Kronenberg, T. (2012) Regional input-output models and the treatment of imports in the European system of accounts. Jahrbuch für Regionalwissenschaft (Review of Regional Research), 32, 175-191. Online First, doi: 10.1007/s10037-012-0065-2.

Kronenberg, T. and J. Többen (2013) Über die Erstellung regionaler Input-Output-Tabellen und die Verbuchung von Importen. In IWH (ed.), Neuere Anwendungsfelder der Input-Output-Analyse. Beiträge zum Halleschen Input-Output-Workshop 2012, Halle (Saale).

Lahr, M.L. (1993) A review of the literature supporting the hybrid approach to constructing regional input-output models. Economic Systems Research, 5, 277-293.

Lahr, M.L. (2001) Reconciling domestication techniques, the notion of re-exports and some comments on regional accounting. Economic Systems Research, 13, 165-179.

Miller, R. E. and P.D. Blair (2009) Input-Output Analysis: Foundations and Extensions, $2^{\text {nd }}$ edition. Cambridge University Press, Cambridge.

National Bureau of Statistics of China (2009) China Statistical Yearbook 2008. China Statistics Press, Beijing.

National Bureau of Statistics of China (2011a) China Statistical Yearbook 2011. China Statistics Press, Beijing.

National Bureau of Statistics of China (2011b) Chinese National and Regional Input-Output Tables 2007. China Statistics Press, Beijing.

Richardson, H.W. (1985) Input-output and economic base multipliers: looking backward and foreward. Journal of Regional Science, 25, 607-661.

Robison, M.H. and J.R. Miller (1988) Cross-hauling and nonsurvey input-output models: some lessons from small-area timber economies. Environment and Planning A, 20, 1523-1530.

Round, J.I. (1972) Regional input-output models in the U.K.: a reappraisal of some techniques. Regional Studies, 6, 1-9.

Tohmo, T. (2004) New developments in the use of location quotients to estimate regional input-output coefficients and multipliers. Regional Studies, 38, 43-54.

United Nations (1973) Input-Output Tables and Analysis. United Nations, New York. 
TABLE 1. Sectoral shares of output and heterogeneity of products in 2007: Province of Hubei and China.

\begin{tabular}{|c|c|c|c|c|c|c|}
\hline \multirow{2}{*}{ Sector } & \multirow{2}{*}{ Description } & \multicolumn{2}{|c|}{ Share of output } & \multirow{2}{*}{$S L Q_{i}$} & \multicolumn{2}{|c|}{ Degree of heterogeneity $\left(h_{i}\right)$} \\
\hline & & Hubei & China & & China & Hubei \\
\hline 1 & Agriculture, forestry, animal husbandry and fishing & 0.104 & 0.060 & 1.740 & 0.0134 & 0.1603 \\
\hline 2 & Coal mining and washing & 0.001 & 0.012 & 0.096 & 0.0200 & 0.0008 \\
\hline 3 & Oil and gas mining & 0.001 & 0.012 & 0.068 & 0.0141 & 0.0120 \\
\hline 4 & Metal mining and selecting & 0.004 & 0.008 & 0.534 & 0.0101 & 0.5963 \\
\hline 5 & Mining and selecting of non-metalliferous ore and other minerals & 0.008 & 0.005 & 1.789 & 0.0383 & 0.0682 \\
\hline 6 & Food manufacturing and tobacco processing & 0.081 & 0.051 & 1.580 & 0.0380 & 0.1723 \\
\hline 7 & Textile industry & 0.036 & 0.031 & 1.168 & 0.0381 & 0.0908 \\
\hline 8 & Manufacturing of textile clothing, shoes, hats, leather and down & 0.024 & 0.022 & 1.102 & 0.0392 & 0.0136 \\
\hline 9 & Wood processing and furniture manufacturing & 0.011 & 0.013 & 0.798 & 0.0273 & 0.0377 \\
\hline 10 & Paper, printing, stationery and sporting goods & 0.018 & 0.018 & 0.973 & 0.0583 & 0.0177 \\
\hline 11 & Oil processing, coking and nuclear fuel processing & 0.013 & 0.026 & 0.488 & 0.0359 & 0.0055 \\
\hline 12 & Chemical industry & 0.057 & 0.076 & 0.755 & 0.1150 & 0.0948 \\
\hline 13 & Manufacturing of non-metallic minerals & 0.033 & 0.028 & 1.170 & 0.0170 & 0.0594 \\
\hline 14 & Metal smelting and press processing & 0.045 & 0.075 & 0.600 & 0.0712 & 0.1452 \\
\hline 15 & Fabricated metal products & 0.024 & 0.022 & 1.098 & 0.0361 & 0.0382 \\
\hline 16 & Manufacturing of general and special equipment & 0.035 & 0.048 & 0.730 & 0.1429 & 0.1411 \\
\hline 17 & Manufacturing of transportation equipment & 0.043 & 0.040 & 1.063 & 0.0915 & 0.2078 \\
\hline 18 & Manufacturing of electrical machinery and equipment & 0.013 & 0.033 & 0.391 & 0.1349 & 0.0870 \\
\hline 19 & $\begin{array}{l}\text { Manufacturing of communication equipment, computers and other } \\
\text { electronic equipment }\end{array}$ & 0.019 & 0.050 & 0.369 & 0.4217 & 0.1571 \\
\hline 20 & $\begin{array}{l}\text { Manufacturing of instruments, equipment for cultural industries, and } \\
\text { office machinery }\end{array}$ & 0.004 & 0.006 & 0.692 & 0.6195 & 0.2349 \\
\hline 21 & Arts, crafts and other manufacturing & 0.005 & 0.008 & 0.650 & 0.0393 & 0.0126 \\
\hline 22 & Waste and scrap & 0.001 & 0.005 & 0.237 & 0.0063 & 0.0282 \\
\hline 23 & Electric power, heat power production and supply & 0.030 & 0.038 & 0.779 & 0.0006 & 0.1537 \\
\hline 24 & Gas production and supply & 0.004 & 0.001 & 3.237 & 0.0000 & 0.0023 \\
\hline 25 & Water production and supply & 0.003 & 0.001 & 2.322 & 0.0000 & 0.0000 \\
\hline 26 & Construction & 0.089 & 0.077 & 1.157 & 0.0035 & 0.0000 \\
\hline 27 & Transport and storage & 0.045 & 0.039 & 1.174 & 0.0352 & 0.0645 \\
\hline 28 & Post & 0.001 & 0.001 & 1.380 & 0.0560 & 0.0227 \\
\hline
\end{tabular}




\begin{tabular}{|c|c|c|c|c|c|c|}
\hline 29 & Information transmission, computer services and software & 0.013 & 0.012 & 1.071 & 0.0399 & 0.0480 \\
\hline 30 & Wholesale and retail trade & 0.046 & 0.035 & 1.314 & 0.0000 & 0.0548 \\
\hline 31 & Hotels and catering services & 0.025 & 0.018 & 1.359 & 0.0356 & 0.0128 \\
\hline 32 & Financial intermediation & 0.023 & 0.024 & 0.981 & 0.0044 & 0.0236 \\
\hline 33 & Real estate & 0.025 & 0.018 & 1.366 & 0.0000 & 0.0000 \\
\hline 34 & Leasing and business services & 0.011 & 0.014 & 0.754 & 0.2118 & 0.0245 \\
\hline 35 & Research and development & 0.002 & 0.002 & 1.118 & 0.0155 & 0.0230 \\
\hline 36 & Comprehensive technology services & 0.004 & 0.005 & 0.783 & 0.0000 & 0.0000 \\
\hline 37 & $\begin{array}{l}\text { Management of water conservancy, environment and public } \\
\text { facilities }\end{array}$ & 0.003 & 0.003 & 1.288 & 0.0000 & 0.0000 \\
\hline 38 & Services to households and other services & 0.013 & 0.011 & 1.234 & 0.0232 & 0.0000 \\
\hline 39 & Education & 0.031 & 0.016 & 1.912 & 0.0020 & 0.0118 \\
\hline 40 & Health, social security and social welfare & 0.017 & 0.014 & 1.249 & 0.0018 & 0.0000 \\
\hline 41 & Culture, sports and entertainment & 0.006 & 0.004 & 1.360 & 0.0860 & 0.0025 \\
\hline \multirow[t]{2}{*}{42} & Public management and social organization & 0.030 & 0.019 & 1.553 & 0.0027 & 0.0000 \\
\hline & Sum or mean & 1.000 & 1.000 & & 0.0606 & 0.0696 \\
\hline
\end{tabular}

Source: Authors' calculations using data from the official input-output tables for China and Hubei in 2007 (National Bureau of Statistics of China, 2011b). 
TABLE 2. Estimation of Hubei trade (millions of yuan) in 2007.

\begin{tabular}{|c|c|c|c|c|c|c|c|c|c|c|c|c|c|}
\hline \multirow[b]{2}{*}{ Sector } & \multicolumn{4}{|c|}{ CHARM } & \multicolumn{4}{|c|}{ CB method } & \multicolumn{5}{|c|}{ Official statistics } \\
\hline & Exports & Imports & $\begin{array}{c}\text { Trade } \\
\text { balance }\end{array}$ & $\begin{array}{c}\text { Trade } \\
\text { volume }\end{array}$ & Exports & Imports & $\begin{array}{c}\text { Trade } \\
\text { balance }\end{array}$ & $\begin{array}{c}\text { Trade } \\
\text { volume }\end{array}$ & Exports & Imports & $\begin{array}{c}\text { Trade } \\
\text { balance }\end{array}$ & $\begin{array}{c}\text { Trade } \\
\text { volume }\end{array}$ & Output \\
\hline 1 & 55938 & 2731 & 53207 & 58669 & 53207 & 0 & 53207 & 53207 & 38654 & 36797 & 1857 & 75451 & 230478 \\
\hline 2 & 220 & 17205 & -16985 & 17424 & 0 & 16985 & -16985 & 16985 & 8 & 16287 & -16279 & 16295 & 2520 \\
\hline 3 & 198 & 24776 & -24578 & 24973 & 0 & 24578 & -24578 & 24578 & 111 & 15134 & -15023 & 15245 & 1745 \\
\hline 4 & 131 & 8193 & -8062 & 8324 & 0 & 8062 & -8062 & 8062 & 7164 & 13395 & -6230 & 20559 & 8901 \\
\hline 5 & 7634 & 580 & 7054 & 8214 & 7054 & 0 & 7054 & 7054 & 1790 & 1255 & 535 & 3045 & 18667 \\
\hline 6 & 46355 & 6029 & 40326 & 52383 & 40326 & 0 & 40326 & 40326 & 40245 & 29921 & 10325 & 70166 & 178833 \\
\hline 7 & 28551 & 2539 & 26012 & 31090 & 26012 & 0 & 26012 & 26012 & 21545 & 6555 & 14990 & 28099 & 79711 \\
\hline 8 & 19090 & 1774 & 17315 & 20864 & 17315 & 0 & 17315 & 17315 & 8460 & 683 & 7777 & 9143 & 53953 \\
\hline 9 & 736 & 647 & 89 & 1383 & 89 & 0 & 89 & 89 & 913 & 1892 & -978 & 2805 & 23761 \\
\hline 10 & 2513 & 2288 & 225 & 4801 & 225 & 0 & 225 & 225 & 743 & 8806 & -8063 & 9549 & 39367 \\
\hline 11 & 1483 & 28522 & -27039 & 30005 & 0 & 27039 & -27039 & 27039 & 204 & 19140 & -18935 & 19344 & 27835 \\
\hline 12 & 16554 & 50965 & -34411 & 67518 & 0 & 34411 & -34411 & 34411 & 12557 & 24118 & -11561 & 36675 & 126726 \\
\hline 13 & 9820 & 1152 & 8669 & 10972 & 8669 & 0 & 8669 & 8669 & 11501 & 4069 & 7432 & 15569 & 72267 \\
\hline 14 & 7924 & 32013 & -24089 & 39937 & 0 & 24089 & -24089 & 24089 & 17098 & 14198 & 2900 & 31296 & 99239 \\
\hline 15 & 19165 & 1581 & 17584 & 20746 & 17584 & 0 & 17584 & 17584 & 12873 & 1799 & 11074 & 14672 & 52654 \\
\hline 16 & 12646 & 33332 & -20685 & 45978 & 0 & 20685 & -20685 & 20685 & 11236 & 14201 & -2966 & 25437 & 78141 \\
\hline 17 & 11811 & 8536 & 3275 & 20347 & 3275 & 0 & 3275 & 3275 & 20013 & 22647 & -2635 & 42660 & 94972 \\
\hline 18 & 5568 & 30714 & -25145 & 36282 & 0 & 25145 & -25145 & 25145 & 2581 & 4510 & -1929 & 7090 & 28697 \\
\hline 19 & 20695 & 36438 & -15743 & 57133 & 0 & 15743 & -15743 & 15743 & 6780 & 10695 & -3915 & 17475 & 41205 \\
\hline 20 & 7154 & 11963 & -4809 & 19117 & 0 & 4809 & -4809 & 4809 & 2508 & 5571 & -3063 & 8078 & 9143 \\
\hline 21 & 470 & 2606 & -2136 & 3077 & 0 & 2136 & -2136 & 2136 & 604 & 134 & 470 & 738 & 10883 \\
\hline 22 & 43 & 8162 & -8118 & 8205 & 0 & 8118 & -8118 & 8118 & 404 & 356 & 48 & 760 & 2799 \\
\hline 23 & 40 & 7046 & -7006 & 7086 & 0 & 7006 & -7006 & 7006 & 27526 & 8777 & 18749 & 36303 & 66487 \\
\hline 24 & 6598 & 0 & 6598 & 6598 & 6598 & 0 & 6598 & 6598 & 2742 & 20 & 2722 & 2761 & 9719 \\
\hline 25 & 4057 & 0 & 4057 & 4057 & 4057 & 0 & 4057 & 4057 & 0 & 0 & 0 & 0 & 7416 \\
\hline 26 & 26521 & 649 & 25872 & 27170 & 25872 & 0 & 25872 & 25872 & 0 & 0 & 0 & 0 & 196670 \\
\hline 27 & 22415 & 3207 & 19209 & 25622 & 19209 & 0 & 19209 & 19209 & 20636 & 6027 & 14610 & 26663 & 100810 \\
\hline 28 & 542 & 142 & 400 & 684 & 400 & 0 & 400 & 400 & 66 & 418 & -352 & 484 & 2733 \\
\hline 29 & 2428 & 1135 & 1294 & 3563 & 1294 & 0 & 1294 & 1294 & 1410 & 1995 & -585 & 3405 & 29105 \\
\hline 30 & 35899 & 0 & 35899 & 35899 & 35899 & 0 & 35899 & 35899 & 15961 & 5336 & 10625 & 21297 & 102634 \\
\hline 31 & 13693 & 1727 & 11966 & 15420 & 11966 & 0 & 11966 & 11966 & 4446 & 676 & 3770 & 5122 & 54532 \\
\hline 32 & 234 & 2314 & -2081 & 2548 & 0 & 2081 & -2081 & 2081 & 1386 & 1220 & 166 & 2606 & 51771 \\
\hline 33 & 13498 & 0 & 13498 & 13498 & 13498 & 0 & 13498 & 13498 & 0 & 0 & 0 & 0 & 54679 \\
\hline
\end{tabular}




\begin{tabular}{|c|c|c|c|c|c|c|c|c|c|c|c|c|c|}
\hline 34 & 5915 & 13615 & -7700 & 19530 & 0 & 7700 & -7700 & 7700 & 1477 & 580 & 897 & 2057 & 24080 \\
\hline 35 & 70 & 759 & -689 & 829 & 0 & 689 & -689 & 689 & 114 & 1646 & -1532 & 1759 & 4176 \\
\hline 36 & 0 & 2481 & -2481 & 2481 & 0 & 2481 & -2481 & 2481 & 0 & 2702 & -2702 & 2702 & 9329 \\
\hline 37 & 1229 & 0 & 1229 & 1229 & 1229 & 0 & 1229 & 1229 & 0 & 0 & 0 & 0 & 7528 \\
\hline 38 & 4663 & 633 & 4030 & 5296 & 4030 & 0 & 4030 & 4030 & 0 & 0 & 0 & 0 & 29263 \\
\hline 39 & 31031 & 103 & 30928 & 31134 & 30928 & 0 & 30928 & 30928 & 3003 & 788 & 2215 & 3791 & 67693 \\
\hline 40 & 7624 & 61 & 7562 & 7685 & 7562 & 0 & 7562 & 7562 & 0 & 0 & 0 & 0 & 37645 \\
\hline 41 & 3563 & 1013 & 2550 & 4575 & 2550 & 0 & 2550 & 2550 & 32 & 129 & -97 & 162 & 13048 \\
\hline 42 & 23741 & 145 & 23596 & 23886 & 23596 & 0 & 23596 & 23596 & 0 & 0 & 0 & 0 & 66554 \\
\hline Sum & 478459 & 347775 & 130685 & 826234 & 362444 & 231759 & 130685 & 594203 & 296790 & 282474 & 14316 & 579264 & 2218368 \\
\hline
\end{tabular}

Source: See Table 1. 
TABLE 3. The impact on the estimates from CHARM of using official Hubei data (millions of yuan) in 2007.

\begin{tabular}{|c|c|c|c|c|c|c|c|c|c|c|c|c|c|c|}
\hline \multirow[b]{2}{*}{ Sector } & \multicolumn{7}{|c|}{ Imports } & \multicolumn{7}{|c|}{ Exports } \\
\hline & $\begin{array}{l}\text { Original } \\
\text { CHARM } \\
\text { estimates }\end{array}$ & $\begin{array}{c}\text { Using } \\
\text { official } f_{i} \\
\text { and } g_{i}\end{array}$ & $\begin{array}{c}\text { Using } \\
\text { official } f_{i} \text {, } \\
g_{i} \text { and } z_{i}\end{array}$ & $\begin{array}{c}\text { Scaling } \\
\text { error }\end{array}$ & $\begin{array}{c}\text { Technology } \\
\text { error }\end{array}$ & $\begin{array}{l}\text { Heterogeneity } \\
\text { error }\end{array}$ & $\begin{array}{l}\text { Official } \\
\text { data for } \\
\text { imports }\end{array}$ & $\begin{array}{l}\text { Original } \\
\text { CHARM } \\
\text { estimates }\end{array}$ & $\begin{array}{c}\text { Using } \\
\text { official } f_{i} \\
\text { and } g_{i}\end{array}$ & $\begin{array}{c}\text { Using } \\
\text { official } f_{i} \text {, } \\
g_{i} \text { and } z_{i}\end{array}$ & $\begin{array}{c}\text { Scaling } \\
\text { error }\end{array}$ & $\begin{array}{c}\text { Technology } \\
\text { error }\end{array}$ & $\begin{array}{c}\text { Heterogeneity } \\
\text { error }\end{array}$ & $\begin{array}{l}\text { Official } \\
\text { data for } \\
\text { exports }\end{array}$ \\
\hline 1 & 2731 & 2943 & 3074 & -212 & -132 & -33723 & 36797 & 55938 & 24492 & 4931 & 31446 & 19561 & -33723 & 38654 \\
\hline 2 & 17205 & 17748 & 16492 & -543 & 1257 & 205 & 16287 & 220 & 225 & 213 & -5 & 12 & 205 & 8 \\
\hline 3 & 24776 & 24887 & 15153 & -111 & 9734 & 19 & 15134 & 198 & 198 & 130 & 0 & 68 & 19 & 111 \\
\hline 4 & 8193 & 8001 & 6352 & 192 & 1649 & -7043 & 13395 & 131 & 130 & 121 & 1 & 8 & -7043 & 7164 \\
\hline 5 & 580 & 596 & 705 & -16 & -109 & -550 & 1255 & 7634 & 6828 & 1240 & 806 & 5588 & -550 & 1790 \\
\hline 6 & 6029 & 23802 & 6599 & -17773 & 17204 & -23322 & 29921 & 46355 & 7112 & 16923 & 39243 & -9812 & -23322 & 40245 \\
\hline 7 & 2539 & 2875 & 2749 & -336 & 126 & -3806 & 6555 & 28551 & 11244 & 17739 & 17307 & -6495 & -3806 & 21545 \\
\hline 8 & 1774 & 2004 & 1961 & -230 & 43 & 1278 & 683 & 19090 & 7606 & 9738 & 11484 & -2133 & 1278 & 8460 \\
\hline 9 & 647 & 7372 & 1640 & -6725 & 5733 & -252 & 1892 & 736 & 739 & 661 & -3 & 77 & -252 & 913 \\
\hline 10 & 2288 & 6956 & 10593 & -4668 & 3637 & 1787 & 8806 & 2513 & 2427 & 2530 & 86 & -103 & 1787 & 743 \\
\hline 11 & 28522 & 30200 & 20273 & -1678 & 9928 & 1133 & 19140 & 1483 & 1512 & 1337 & -29 & 175 & 1133 & 204 \\
\hline 12 & 50965 & 62815 & 26801 & -11850 & 36015 & 2683 & 24118 & 16554 & 17198 & 15240 & -644 & 1958 & 2683 & 12557 \\
\hline 13 & 1152 & 1199 & 1162 & -47 & 37 & -2906 & 4069 & 9820 & 4284 & 8595 & 5536 & -4311 & -2906 & 11501 \\
\hline 14 & 32013 & 33986 & 6963 & -1973 & 27023 & -7235 & 14198 & 7924 & 7992 & 9863 & -68 & -1872 & -7235 & 17098 \\
\hline 15 & 1581 & 1626 & 1699 & -45 & -72 & -100 & 1799 & 19165 & 16708 & 12772 & 2457 & 3936 & -100 & 12873 \\
\hline 16 & 33332 & 38569 & 14346 & -5237 & 24224 & 144 & 14201 & 12646 & 12996 & 11380 & -350 & 1616 & 144 & 11236 \\
\hline 17 & 8536 & 39327 & 11441 & -30791 & 27887 & -11207 & 22647 & 11811 & 10025 & 8806 & 1786 & 1219 & -11207 & 20013 \\
\hline 18 & 30714 & 22927 & 5931 & 7787 & 16996 & 1422 & 4510 & 5568 & 5076 & 4002 & 492 & 1074 & 1422 & 2581 \\
\hline 19 & 36438 & 46134 & 22117 & -9696 & 24017 & 11421 & 10695 & 20695 & 22383 & 18201 & -1688 & 4182 & 11421 & 6780 \\
\hline 20 & 11963 & 13434 & 9676 & -1471 & 3758 & 4105 & 5571 & 7154 & 7502 & 6613 & -348 & 889 & 4105 & 2508 \\
\hline 21 & 2606 & 372 & 419 & 2234 & -47 & 285 & 134 & 470 & 3232 & 889 & -2762 & 2343 & 285 & 604 \\
\hline 22 & 8162 & 7561 & 17 & 601 & 7543 & -338 & 356 & 43 & 41 & 66 & 2 & -24 & -338 & 404 \\
\hline 23 & 7046 & 9912 & 33 & -2866 & 9879 & -8744 & 8777 & 40 & 41 & 18781 & -1 & -18740 & -8744 & 27526 \\
\hline 24 & 0 & 0 & 0 & 0 & 0 & -20 & 20 & 6598 & 4469 & 2722 & 2129 & 1747 & -20 & 2742 \\
\hline 25 & 0 & 0 & 0 & 0 & 0 & 0 & 0 & 4057 & 2758 & 0 & 1299 & 2758 & 0 & 0 \\
\hline 26 & 649 & 662 & 695 & -13 & -32 & 695 & 0 & 26521 & 18981 & 695 & 7540 & 18286 & 695 & 0 \\
\hline 27 & 3207 & 3380 & 3287 & -173 & 92 & -2739 & 6027 & 22415 & 12744 & 17897 & 9671 & -5153 & -2739 & 20636 \\
\hline 28 & 142 & 141 & 515 & 1 & -374 & 97 & 418 & 542 & 566 & 163 & -24 & 404 & 97 & 66 \\
\hline 29 & 1135 & 6448 & 1757 & -5313 & 4690 & -238 & 1995 & 2428 & 1264 & 1172 & 1164 & 92 & -238 & 1410 \\
\hline 30 & 0 & 0 & 0 & 0 & 0 & -5336 & 5336 & 35899 & 22039 & 10625 & 13860 & 11414 & -5336 & 15961 \\
\hline 31 & 1727 & 5543 & 1873 & -3816 & 3670 & 1197 & 676 & 13693 & 2003 & 5643 & 11690 & -3640 & 1197 & 4446 \\
\hline 32 & 2314 & 4475 & 229 & -2161 & 4246 & -991 & 1220 & 234 & 238 & 395 & -4 & -157 & -991 & 1386 \\
\hline 33 & 0 & 0 & 0 & 0 & 0 & 0 & 0 & 13498 & 27834 & 0 & -14336 & 27834 & 0 & 0 \\
\hline 34 & 13615 & 10265 & 5005 & 3350 & 5261 & 4425 & 580 & 5915 & 5594 & 5902 & 321 & -308 & 4425 & 1477 \\
\hline
\end{tabular}




\begin{tabular}{|c|c|c|c|c|c|c|c|c|c|c|c|c|c|c|}
\hline 35 & 759 & 59 & 1609 & 700 & -1550 & -37 & 1646 & 70 & 795 & 77 & -725 & 719 & -37 & 114 \\
\hline 36 & 2481 & 0 & 2702 & 2481 & -2702 & 0 & 2702 & 0 & 187 & 0 & -187 & 187 & 0 & 0 \\
\hline 37 & 0 & 0 & 0 & 0 & 0 & 0 & 0 & 1229 & 741 & 0 & 488 & 741 & 0 & 0 \\
\hline 38 & 633 & 565 & 680 & 68 & -115 & 680 & 0 & 4663 & 10443 & 680 & -5780 & 9763 & 680 & 0 \\
\hline 39 & 103 & 126 & 132 & -23 & -6 & -656 & 788 & 31031 & 8274 & 2346 & 22757 & 5928 & -656 & 3003 \\
\hline 40 & 61 & 58 & 68 & 3 & -10 & 68 & 0 & 7624 & 11490 & 68 & -3866 & 11422 & 68 & 0 \\
\hline 41 & 1013 & 993 & 1223 & 20 & -230 & 1094 & 129 & 3563 & 4004 & 1126 & -441 & 2877 & 1094 & 32 \\
\hline 42 & 145 & 176 & 177 & -31 & -1 & 177 & 0 & 23741 & 925 & 177 & 22816 & 749 & 177 & 0 \\
\hline Sum & 347775 & 438138 & 206145 & -90363 & 231993 & -76329 & 282474 & 478459 & 305340 & 220461 & 173119 & 84879 & -76329 & 296790 \\
\hline
\end{tabular}

Source: See Table 1. 
TABLE 4. Alternative estimates of supply multipliers in 2007: Province of Hubei.

\begin{tabular}{|c|c|c|c|c|c|c|}
\hline Sector & $\begin{array}{c}\text { CB } \\
\text { method }\end{array}$ & CHARM & $\begin{array}{c}\text { Scaling } \\
\text { error }\end{array}$ & $\begin{array}{c}\text { Technology } \\
\text { error }\end{array}$ & $\begin{array}{c}\text { Heterogeneity } \\
\text { error }\end{array}$ & Official data \\
\hline 1 & 1.920 & 1.862 & 0.040 & 0.048 & 0.126 & 1.648 \\
\hline 2 & 1.145 & 1.135 & 0.008 & -0.011 & 0.002 & 1.137 \\
\hline 3 & 1.059 & 1.055 & 0.002 & -0.056 & 0.002 & 1.107 \\
\hline 4 & 1.728 & 1.684 & 0.013 & -0.215 & 0.302 & 1.583 \\
\hline 5 & 2.366 & 2.243 & 0.045 & -0.049 & 0.058 & 2.190 \\
\hline 6 & 2.653 & 2.529 & 0.194 & -0.037 & 0.233 & 2.138 \\
\hline 7 & 3.117 & 2.928 & 0.062 & 0.204 & 0.135 & 2.527 \\
\hline 8 & 3.175 & 2.976 & 0.064 & 0.285 & 0.018 & 2.609 \\
\hline 9 & 2.912 & 2.756 & 0.520 & -0.076 & 0.039 & 2.272 \\
\hline 10 & 2.866 & 2.632 & 0.267 & 0.132 & -0.040 & 2.274 \\
\hline 11 & 1.548 & 1.521 & 0.022 & -0.280 & -0.009 & 1.788 \\
\hline 12 & 2.394 & 2.172 & 0.122 & -0.087 & -0.013 & 2.150 \\
\hline 13 & 2.643 & 2.532 & 0.050 & 0.122 & 0.080 & 2.280 \\
\hline 14 & 2.347 & 2.200 & 0.044 & -0.136 & 0.152 & 2.140 \\
\hline 15 & 2.904 & 2.732 & 0.054 & 0.350 & 0.053 & 2.275 \\
\hline 16 & 2.417 & 2.152 & 0.083 & -0.034 & 0.030 & 2.073 \\
\hline 17 & 3.142 & 2.771 & 0.555 & -0.023 & 0.146 & 2.092 \\
\hline 18 & 2.018 & 1.844 & -0.110 & -0.136 & -0.023 & 2.113 \\
\hline 19 & 2.434 & 1.868 & 0.139 & 0.007 & -0.187 & 1.909 \\
\hline 20 & 2.221 & 1.689 & 0.072 & -0.027 & -0.189 & 1.834 \\
\hline 21 & 2.533 & 2.390 & -0.223 & 0.039 & -0.023 & 2.597 \\
\hline 22 & 1.072 & 1.070 & -0.003 & -0.256 & 0.035 & 1.294 \\
\hline 23 & 2.329 & 2.275 & 0.082 & 0.276 & 0.102 & 1.815 \\
\hline 24 & 2.129 & 2.097 & 0.024 & 0.495 & 0.003 & 1.575 \\
\hline 25 & 2.214 & 2.156 & 0.045 & -0.115 & 0.005 & 2.221 \\
\hline 26 & 2.834 & 2.723 & 0.045 & 0.028 & 0.043 & 2.607 \\
\hline 27 & 2.106 & 2.010 & 0.060 & -0.040 & 0.046 & 1.943 \\
\hline 28 & 2.186 & 2.047 & 0.072 & 0.102 & -0.015 & 1.888 \\
\hline 29 & 1.871 & 1.751 & 0.133 & 0.092 & -0.002 & 1.528 \\
\hline 30 & 1.876 & 1.816 & 0.032 & 0.286 & 0.026 & 1.471 \\
\hline 31 & 2.461 & 2.351 & 0.154 & 0.010 & 0.041 & 2.145 \\
\hline 32 & 1.622 & 1.579 & 0.045 & -0.127 & 0.005 & 1.656 \\
\hline 33 & 1.367 & 1.341 & 0.010 & -0.265 & -0.006 & 1.602 \\
\hline 34 & 2.207 & 1.926 & -0.039 & -0.039 & -0.187 & 2.191 \\
\hline 35 & 2.120 & 2.002 & -0.126 & 0.532 & 0.009 & 1.588 \\
\hline 36 & 1.802 & 1.725 & -0.168 & 0.370 & 0.002 & 1.521 \\
\hline 37 & 2.098 & 2.020 & 0.047 & 0.414 & 0.003 & 1.556 \\
\hline 38 & 2.270 & 2.138 & 0.066 & 0.179 & -0.021 & 1.914 \\
\hline 39 & 2.016 & 1.942 & 0.052 & 0.302 & 0.000 & 1.588 \\
\hline 40 & 2.561 & 2.434 & 0.071 & 0.169 & 0.000 & 2.194 \\
\hline 41 & 2.388 & 2.200 & 0.066 & 0.297 & -0.064 & 1.900 \\
\hline 42 & 2.071 & 1.999 & 0.064 & 0.279 & -0.005 & 1.661 \\
\hline Mean & 2.218 & 2.078 & 0.066 & 0.072 & 0.022 & 1.919 \\
\hline
\end{tabular}

Source: See Table 1. 
Recent UWE Economics Papers

See http://www1.uwe.ac.uk/bl/research/bristoleconomicanalysis for a full list.

1506 Using CHARM to adjust for cross-hauling: the case of the Province of Hubei, China Anthony T. Flegg, Yongming Huang and Timo Tohmo

1505 University entrepreneurship education experiences: enhancing the entrepreneurial ecosystems in a UK city-region

Fumi Kitagawa, Don J. Webber, Anthony Plumridge and Susan Robertson

1504 Can indeterminacy and self-fulfilling expectations help explain international business cycles?

Stephen McKnight and Laura Povoledo

1503 User-focused threat identification for anonymised microdata

Hans-Peter Hafner, Felix Ritchie and Rainer Lenz

1502 Reflections on the one-minute paper

Damian Whittard

1501 Principles- versus rules-based output statistical disclosure control in remote access environments Felix Ritchie and Mark Elliot

1413 Addressing the human factor in data access: incentive compatibility, legitimacy and cost-effectiveness in public data resources

Felix Ritchie and Richard Welpton

1412 Resistance to change in government: risk, inertia and incentives Felix Ritchie

1411 Emigration, remittances and corruption experience of those staying behind Artjoms Ivlevs and Roswitha M. King

1410 Operationalising 'safe statistics': the case of linear regression Felix Ritchie

1409 Is temporary employment a cause or consequence of poor mental health? Chris Dawson, Michail Veliziotis, Gail Pacheco and Don J Webber

1408 Regional productivity in a multi-speed Europe

Don J. Webber, Min Hua Jen and Eoin O'Leary

1407 Assimilation of the migrant work ethic

Chris Dawson, Michail Veliziotis, Benjamin Hopkins

1406 Empirical evidence on the use of the FLQ formula for regionalizing national input-output tables: the case of the Province of Córdoba, Argentina

Anthony T. Flegg, Leonardo J. Mastronardi and Carlos A. Romero

1405 Can the one minute paper breathe life back into the economics lecture?

Damian Whittard

1404 The role of social norms in incentivising energy reduction in organisations

Peter Bradley, Matthew Leach and Shane Fudge 
1403 How do knowledge brokers work? The case of WERS

Hilary Drew, Felix Ritchie and Anna King

1402 Happy moves? Assessing the impact of subjective well-being on the emigration decision Artjoms Ivlevs

1401 Communist party membership and bribe paying in transitional economies

Timothy Hinks and Artjoms Ivlevs

1315 Global economic crisis and corruption experience: Evidence from transition economies Artjoms Ivlevs and Timothy Hinks

1314 A two-state Markov-switching distinctive conditional variance application for tanker freight returns Wessam Abouarghoub, Iris Biefang-Frisancho Mariscal and Peter Howells

1313 Measuring the level of risk exposure in tanker shipping freight markets Wessam Abouarghoub and Iris Biefang-Frisancho Mariscal

1312 Modelling the sectoral allocation of labour in open economy models Laura Povoledo

1311 The US Fed and the Bank of England: ownership, structure and 'independence' Peter Howells

1310 Cross-hauling and regional input-output tables: the case of the province of Hubei, China Anthony T. Flegg, Yongming Huang and Timo Tohmo

1309 Temporary employment, job satisfaction and subjective well-being Chris Dawson and Michail Veliziotis

1308 Risk taking and monetary policy before the crisis: the case of Germany Iris Biefang-Frisancho Mariscal

1307 What determines students' choices of elective modules? Mary R Hedges, Gail A Pacheco and Don J Webber

1306 How should economics curricula be evaluated? Andrew Mearman

1305 Temporary employment and wellbeing: Selection or causal? Chris Dawson, Don J Webber and Ben Hopkins

1304 Trade unions and unpaid overtime in Britain Michail Veliziotis

1303 Why do students study economics? Andrew Mearman, Aspasia Papa and Don J. Webber

1302 Estimating regional input coefficients and multipliers: The use of the FLQ is not a gamble Anthony T. Flegg and Timo Tohmo 